\title{
DESENVOLVIMENTO DE UM INSTRUMENTO PARA AVALIAR A MOVIMENTAÇÃO \\ E TRANSFERENCIA DE CLIENTES: UM ENFOQUE ERGONÔMICO ${ }^{1}$
}

\author{
DEVELOPMENT OF AN INSTRUMENT FOR ASSESSING PATIENT HANDLING \\ TASK: AN ERGONOMIC APPROACH
}

\section{DESARROLO DE UN APARATO PARA EVALUAR LA MOVIMENTACIÓN Y TRANSFERENCIA DE CLIENTES: ENFOQUE ERGONOMICO}

\author{
Cremilde Aparecida Trindade Radovanovic* \\ Neusa Maria Costa Alexandre**
}

Radovanovic CAT, Alexandre NMC. Desenvolvimento de um instrumento para avaliar a movimentação e transferência de clientes: um enfoque ergonômico. Rev Esc Enferm USP 2002; 36(3): 231-9.

\section{RESUMO}

Os distúrbios osteomusculares relacionados ao trabalho, particularmente a dor e as lesões na região lombar, representam um risco para os trabalhadores de enfermagem. Esses profissionais são especialmente suscetiveis a problemas vertebrais pelo fato de terem que movimentar e transportar pacientes regularmente. O objetivo desta pesquisa foi descrever o desenvolvimento de um instrumento para avaliar os riscos ergonômicos durante os procedimentos de movimentação e transferência de clientes. Para ser desenvolvido teve como referencial teórico a ergonomia, o que abrange a interação entre os equipamentos, as atividades, o ambiente e o próprio trabalhador.

PALAVRAS-CHAVE: Dor lombar. Transferência de pacientes. Ergonomia.

\begin{abstract}
Nursing personnel are at a high risk from work-related musculoskeletal disorders, especially back symptoms. Handling patients has been attributed as one of the factors playing an important role in the aetiology of occupational low back pain. The aim of the study was to construct an instrument to evaluate the ergonomic risks during patient-handling tasks. The instrument was developed with an ergonomic approach involving the equipment, the tasks, the environment and the personnel.
\end{abstract}

KEYWORDS: Low back pain. Patient handling. Ergonomics.

\section{RESUME}

Los disturbios osteomusculares relacionados al trabajo, particularmente al dolor y lesiones en la región lombar, representam risco para los trabajadores de enfermeria. Esos profissionales son especialmente suscetibles a problemas vertebrales por el hecho de tener que mobilizar y trasporta regularmente a .los clientes. El objetivo de este estudio es descrevir el desarrollo de un aparato para evaluar los riscos ergonomicos durante el procedimiento de movimentación y transferencia de clientes. Para su desarrollo tuvimos como referencial teorico la ergonomia la que engloba la interación entre los equipamientos, las actividades, el ambiente y el proprio trabajador.

PALABRAS-CLAVE: Dolor lombar. Transferencia de pacientes. Ergonomia.

1 Parte da dissertação de Mestrado, apresentada ao Programa de Pós-Graduação do Departamento de Enfermagem da Faculdade de Ciências Médicas - UNICAMP.

* $\quad$ Aluna do Curso de Mestrado do Departamento de Enfermagem da Faculdade de Ciências Médicas - UNICAMP. Bolsista CNPq - E-mail: kikanovic@bol.com.br

* $\quad$ Professor Assistente Doutor do Departamento de Enfermagem da Faculdade de Ciências Médicas UNICAMP. E-mail: neusalex@fcm.unicamp.br 


\section{INTRODUÇÃO}

A algia vertebral representa a forma mais comum de distúrbios musculoesqueléticos relacionados ao trabalho, resultando em custos substanciais para a sociedade (1).

Os trabalhadores de enfermagem apresentam uma ocorrência elevada de dor lombar, quando comparados a outros grupos de profissionais (2-7) Vários autores relatam determinados fatores de risco entre esses trabalhadores, para a dor lombar como: trabalho repetitivo (8'9); movimentação e transferência de pacientes (10,11); espaço de trabalho restrito (12'13); falta de treinamento para o uso de equipamentos (14); técnicas e práticas de levantamento impróprias(14'15); posturas inadequadas (8,13,16); uniformes incorretos; inaptidão física do funcionário (14,17); insatisfação no trabalho ${ }^{(14)}$ e o esforço físico ${ }^{(1)}$.

Ressalta-se que inúmeros pesquisadores constataram que as dores nas costas entre os profissionais de enfermagem são causadas principalmente devido ao levantamento e à movimentação de clientes (4,10-12,18-20). Dentro desse contexto, a prevenção de dor lombar está baseada basicamente no treinamento do trabalhador de enfermagem em técnicas de movimentação de pacientes ou na redução da excessiva manipulação $(18,21,22)$

No entanto, um elemento importante para qualquer programa de prevenção baseado na ergonomia, nas instituições de saúde, envolve identificar riscos e apresentar métodos para minimizalos. Como os procedimentos de movimentação e transferência de clientes envolvem riscos para os trabalhadores de enfermagem, sentiu-se a necessidade de contribuir para a prevenção das algias vertebrais utilizando-se como referencial teórico a ergonomia. A ergonomia oferece dados e conhecimentos sobre o homem, suas capacidades e habilidades e também sobre suas limitações físicas e psíquicas. Esses dados e conhecimentos podem apoiar e orientar o planejamento e a execução de medidas preventivas de acidentes do trabalho e de doenças ocupacionais. De maneira geral pode-se dizer que a ergonomia atua na adaptação do trabalho, da técnica, do meio ambiente às pessoas e contribui na adaptação das mesmas ao trabalho ${ }^{(23) .}$

Dentro deste contexto, o presente estudo tem como objetivo apresentar o desenvolvimento e descrever um instrumento para avaliar os riscos ergonômicos durante os procedimentos de movimentação e transferência de clientes.

\section{DESENVOLVIMENTO E DESCRIÇÃO DO INSTRUMENTO}

O presente instrumento foi desenvolvido com o objetivo de avaliar riscos ergonômicos presentes durante os procedimentos de movimentação e transferência de clientes. Com os resultados, os trabalhadores da área de saúde terão condições de planejar de uma forma sistemática as necessidades dos clientes, as técnicas adequadas e os equipamentos auxiliares que deverão ser utilizados. Poderá ser utilizado na clinica para um planejamento da assistência e para avaliar a evolução do cliente relacionada à sua dependência e necessidades durante os procedimentos de movimentação e transferência. Poderá ser também usado em pesquisas relacionadas com o tema.

Para ser desenvolvido teve como referencial teórico a ergonomia, o que abrange a interação entre os equipamentos, as atividades, o ambiente e o próprio trabalhador. Dentro desse contexto, as habilidades em movimentação devem ser complementadas com o estabelecimento de práticas seguras de trabalho dentro de uma estrutura ergonômica e com o uso de equipamentos auxiliares. Para alcançar essa meta um dos primeiros passos envolve uma avaliação sistemática das condições e necessidades dos clientes.

$\mathrm{O}$ instrumento constitui-se em uma escala que deve ser preenchida por um trabalhador da saúde, podendo fazer parte dos registros do cliente. Compreende oito tópicos, com três respectivas alternativas, com valores estabelecidos de 1 a 3 . Esses tópicos são: peso, altura, nivel de consciência e psicomotricidade, mobilidade na cama, transferência da cama/maca ou cama/cadeira e vice-versa, deambulação, cateteres e equipamentos utilizados pelo cliente e ambiente. Cada um desses tópicos será descrito a seguir:

\section{1 - Peso}

$1=$ equivale ao peso até $50 \mathrm{~kg}$;

$2=$ indica um peso de $51 \mathrm{~kg}$ a $69 \mathrm{~kg}$;

3= o cliente deverá pesar igual ou superior a $70 \mathrm{~kg}$.

Ao desenvolver um método para avaliar o esforço percebido durante o levantamento de clientes, dividiu-se o peso do cliente como sendo leve, moderado e pesado. $O$ item leve corresponde a um peso até 50 $\mathrm{kg}$, o moderado de $51 \mathrm{~kg}$ a $69 \mathrm{~kg}$, e igual ou superior a $70 \mathrm{~kg}$, foi classificado como pesado (24),

\section{2 - Altura}

$1=$ equivale a uma altura até $1,50 \mathrm{~m}$;

$2=$ equivale a altura entre $1,51 \mathrm{~m} \mathrm{e} 1,79 \mathrm{~m}$;

$3=$ indica uma estatura igual ou superior a $1,80 \mathrm{~m}$.

A altura do cliente foi classificada em três categorias, baixa, média e alta. A estatura baixa refere- 
se a altura de $1,50 \mathrm{~m}$, a média corresponde a uma altura entre $1,51 \mathrm{~m}$ a $1,79 \mathrm{~m}$, e a estatura alta equivale a igual ou superior a $1,80 \mathrm{~m}{ }^{(25)}$

\section{3 - Nivel de consciência e psicomotricidade}

$1=$ alerta: $\mathrm{o}$ cliente responde apropriadamente aos mínimos estímulos, e na ausência deles está desperto e parece perceber o meio;

$2=$ confusão/letargia:

- confusão: o cliente tem alteração ainda que transitória do nível de consciência, e alteração da orientação e atenção, possiveis (mas não é obrigatória) distúrbios da senso-percepção (ilusões, alucinações) e do julgamento (idéias delirantes). Pode apresentar alguma inquietação motora;

- letargia: o cliente pode parecer lento ou hesitante ao falar, aos estímulos tátil e verbal ele responde apropriadamente e torna-se mais alerta, pode manifestar confusão diante de problemas complexos;

\section{- 3= inconsciência/agitação motora:}

- inconsciência: o cliente não percebe impressões sensoriais devido a alterações estruturais/funcionais ou por indução de drogas;

- agitação psicomotora: é a aceleração e exaltação de toda atividade motora do indivíduo, geralmente secundária a um taquipsiquismo acentuado. Comumente associa-se à hostilidade e à heteroagressividade.

Dentro do nível de consciência e psicomotricidade existem algumas divisões, que foram definidas após a revisão de bibliografia específica, levando em consideração o que deve ser observado antes de se realizar a movimentação e transferência do cliente. Desta maneira foram definidos os estados de alerta e a letargia (26) e de confusão mental e agitação psicomotora ${ }^{(27)}$.

O outro item que deve ser avaliado é a inconsciência, que pode ser tanto por alterações funcionais como induzida por drogas (28).

\section{4 - Mobilidade na cama}

$1=$ independente: o cliente realiza todos os movimentos, mexe os membros inferiores e superiores, vira o corpo para os lados, senta-se na cama, sem necessitar de auxilio;

$2=$ movimenta-se com auxilio: o cliente mexe os membros inferiores e superiores, consegue virar parcialmente o corpo para os lados e só se senta na cama com auxilio;

$3=$ dependente: $\mathrm{o}$ cliente não consegue mexer os membros inferiores e superiores, e depende totalmente da equipe de enfermagem.

Os itens relacionados à mobilidade na cama, transferência da cama/maca ou cama/cadeira e viceversa, e deambulação, foram desenvolvidos tendo como suporte teórico o Índice Barthel (29), o The Kenny SelfCare Evalution e o Index of Independence in Activities of Daily Living (ADL) (30)

O Índice de Barthel tem como objetivo avaliar a independência do cliente. Os clientes com desordens neuromusculares ou musculoesqueléticas são periodicamente submetidos a uma avaliação na qual é construída uma pontuação da sua habilidade de autocuidados. $\mathrm{O}$ resultado dessa pontuação pode servir para quantificar o nivel de melhora do cliente (29).

A avaliação de autocuidado de Kenny registra o desempenho funcional para estimar a habilidade de um cliente em viver em sua casa ou em uma instituição, de forma independente (30)

$\mathrm{O}$ índice de independência das atividades diárias (ADL) foi desenvolvido para medir a capacidade fisica de idosos e clientes com doenças crônicas. Freqüentemente tem sido usado para indicar a severidade da doença crônica e para avaliar a efetividade do tratamento, sendo também usado para fornecer informações preditivas sobre o decorrer de doenças específicas (30)

\section{5 - Transferência da cama/maca ou carnal cadeira e vice-versa}

$1=$ independente: o cliente consegue realizar todos os movimentos sozinho, mexe os membros superiores e inferiores, vira o corpo, senta-se na cama e transferese sem ajuda, e faz o processo de retorno para cama;

$2=$ transfere-se com auxilio: o cliente consegue mexer os membros superiores e inferiores, vira parcialmente o corpo e para sentar-se na cama e transferir-se necessita da supervisão e auxílio da equipe de enfermagem, como também para fazer o processo de retorno para a mesma;

3 = dependente: $\mathrm{o}$ cliente não realiza nenhum movimento citado acima, depende totalmente da equipe de enfermagem.

\section{6- Deambulação}

$1=$ independente: $\mathrm{o}$ cliente deambula sem necessitar de auxilio da enfermagem/órteses e próteses;

2 = deambula com auxílio: $\mathrm{o}$ cliente necessita de auxílio e supervisão da equipe de enfermagem;

$3=$ dependente: $o$ cliente não deambula.

\section{7 - Cateteres e equipamentos utilizados pelo cliente}

1 = Até um acessório: $\mathrm{o}$ cliente não possui nenhum ou até um acessório ou equipamento conectado;

2 = Dois a quatro acessórios: 0 cliente possui de dois até quatro acessórios ou equipamentos conectados;

3= Mais de cinco acessórios: o cliente possui cinco ou mais acessórios e equipamentos conectados.

Consideraram-se acessórios e cateteres: sonda vesical, nasogástrica/enteral, drenos, soros, cateteres periféricos e centrais, bolsas de colostomia. 
Os equipamentos que devem ser observados são: monitores, respiradores, bomba de infusão, oxímetros, máquina de hemodiálise, balão intra-aórtico, gerador de marcapasso, colchão hipo/hipertérmico, tração transesquelética e cutânea.

A movimentação e a transferência de clientes tais como sondas, soros, drenos, cateteres, monitores, respiradores, bombas de infusão, máquinas de hemodiálise ${ }^{(12,31,32)}$ Dentro deste contexto e tendo como referencial teórico a literatura sobre o tema, foi desenvolvido o item sete.

\section{8 - Ambiente do cliente}

$1=$ bom: quando o ambiente não proporciona risco para equipe de enfermagem, durante o processo de movimentação e transferência do cliente. Possui espaço físico e piso adequados, cama com altura ajustável, maca/cama e cadeira com travas nas rodas;

$2=$ potencial para risco: tem a presença de um dos fatores de risco, tais como espaço fisico restrito, piso irregular ou cama sem altura ajustável, maca/cama e cadeira sem travas na rodas, dificultando a movimentação ou a transferência do cliente;

$3=$ risco: quando o ambiente apresenta dois ou mais dos fatores de risco como piso irregular, espaço físico restrito ou cama sem altura ajustável, maca/cama e cadeira sem travas na rodas.

A escolha dos fatores que deveriam fazer parte do item 'ambiente' foi selecionada de acordo com as recomendações de publicações sobre o tema (31-37)

Considerou-se como espaço mínimo entre uma cama e outra o equivalente a 1,0 m. Em relação a distância mínima requerida entre a cama e a parede lateral, foi considerada como sendo 0,5 metros (38). A área mínima da UTI foi considerada $9 \mathrm{~m} 2 /$ leito(39)

\section{DETERMINAÇÃO DOS ESCORES}

Por meio de observação e entrevista o trabalhador da saúde pode determinar os valores de cada tópico em uma escala de 1 a 3 . Desta maneira como o instrumento é constituído por oito tópicos, o escore mínimo possivel de ser obtido são oito pontos e o escore máximo são 24 pontos, havendo 17 pontos de variação entre o escore mínimo e o máximo. Dividindose o valor 17 pelas três categorias (pouco, médio e muito risco) obteve-se uma variação de 5,6 pontos por categoria. Optou-se por determinar a categoria pouco risco com uma variação de cinco pontos, sendo que as categorias médio e muito risco ficaram com uma variação de seis pontos.

Dessa forma, a avaliação de riscos a partir dos dados obtidos deverá ser realizada através da pontuação pré-estabelecida, pouco, médio e muito risco:
08-12= Pouco risco durante a movimentação e transferência do cliente;

13-18= Médio risco durante a movimentação e transferência do cliente;

19-24= Muito risco durante a movimentação e transferência do cliente.

Com esses parâmetros, a equipe de enfermagem terá condições de planejar o melhor método de movimentação e transferência do cliente:

08-12= Não necessita de auxílio, requer supervisão da equipe de enfermagem;

13-18= Necessita de planejamento, auxílio da equipe de enfermagem e de pequenos equipamentos (plásticos deslizantes, pranchas, cintos, barra tipo trapézio no leito, escada de cordas, discos giratórios, tábua de transferência, blocos de mão antiderrapantes);

19-24= Necessita de um rigoroso planejamento, auxílio da equipe de enfermagem e de equipamentos mecânicos (elevadores mecânicos).

\section{VALIDADE DO CONTEÚDO E ESTUDO PILOTO}

A validade do conteúdo preocupa-se em analisar minuciosamente o conteúdo do instrumento, com a finalidade de verificar se os itens propostos constituemse numa amostra representativa do assunto que se deseja medir. Esta avaliação pode ser realizada por peritos no assunto, que irão sugerir quanto a retirada, acréscimo ou modificação dos itens ${ }^{(4041)}$ ou por alguns membros da população alvo(42)

No presente estudo, para a avaliação da validade do conteúdo, o instrumento foi submetido à apreciação de seis especialistas, com experiência na área. O instrumento foi apresentado a cada um dos validadores, que foram devidamente instruídos. Após a exposição dos objetivos da pesquisa, foi solicitado que os juizes analisassem e elaborassem sugestões quanto a objetividade, a completude, a adequação e a clareza do instrumento.

Os seis juízes eram enfermeiros, sendo três docentes do Departamento de Enfermagem e três enfermeiros que atuam na área assistencial e administrativa de um Hospital Universitário. Todos tinham mais de três anos de experiência profissional.

Os juizes analisaram o formato, os tópicos da escala, os valores de cada tópico, bem como a classificação dos escores para avaliação dos riscos. As sugestões dadas pelos juízes podem ser observadas na Fig. 1. 


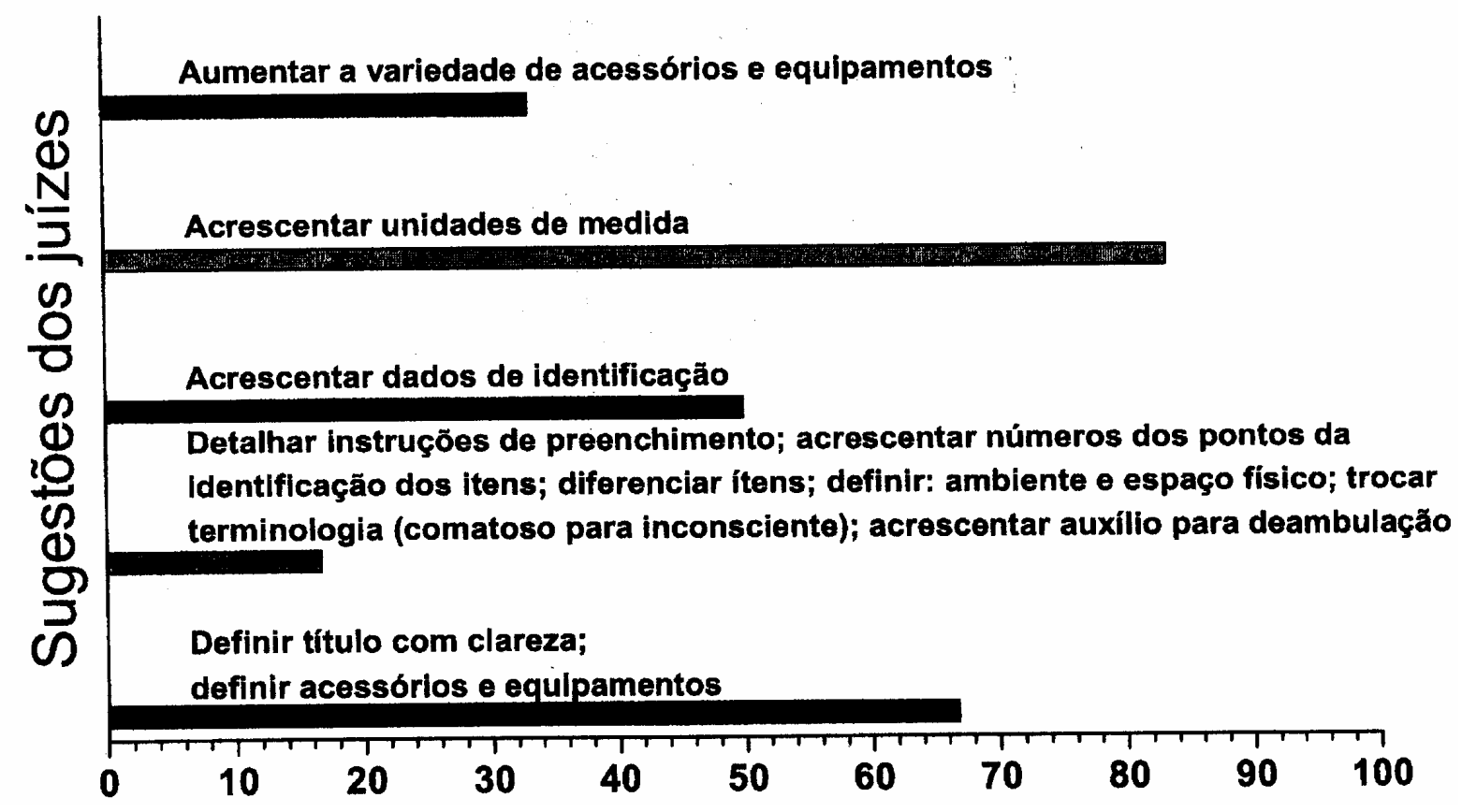

Figura 1. Sugestões apresentadas pelos juizes na avaliação do instrumento quanto à validade do conteúdo.

Entre os juizes quatro fizeram uma observação quanto a falta de clareza do título do instrumento, sugerindo a sua modificação, e um questionou as instruções de preenchimento do instrumento. Foi proposto por três dos juízes que deveriam ser acrescentados na identificação da escala a unidade e o leito do cliente.

Quanto ao formato e estética do instrumento, um dos juízes sugeriu que fosse acrescentada a palavra 'pontos' na identificação dos itens do instrumento e um que fosse diferenciado um item do outro, para facilitar no processo de preenchimento.

Os dois primeiros itens, 'peso' e 'altura', foram questionados por cinco dos juízes, pois não apresentavam a identificação das unidades de medidas (kilograma e metro).

Em relação ao tópico 'nivel de consciência' foi sugerida a troca da terminologia 'comatoso' para 'inconsciência' por um dos juizes. Além disso, três dos participantes indicaram a necessidade da redefinição de alguns dos subitens.

Para os itens 'mobilidade na cama' e 'transferência', as sugestões foram relacionadas à estrutura da escrita, não tendo sugestão quanto aos passos de orientação. Quanto ao item 'deambulação' um dos juízes questionou que deveria ser explicitado o item independente, sugerindo que fosse acrescentado o termo 'sem auxilio' e 'com auxilio da enfermagem' e a introdução de próteses e próteses.

Foi sugerida no item relacionado a acessórios e equipamentos por quatro dos juizes a separação das definições de 'acessórios' e 'equipamentos', sendo que dois fizeram uma observação quanto a variedade de acessórios e equipamentos, sugerindo que fossem acrescentadas mais opções.
O último tópico relacionado ao 'ambiente' foi questionado por um dos juízes, quando foi sugerida uma melhor definição deste item, e um orientou que fosse definido o que é um bom espaço físico.

Em função desta etapa a escala sofreu as seguintes modificações:

- Foram alterados o título, os dados de identificação, a estruturação e a estética;

- Foram acrescentadas unidades de medidas nos itens relacionados a peso e altura;

- Foi aumentada a variedade de acessórios e equipamentos;

- Foi reformulado o conteúdo de alguns subitens, visando facilitar o preenchimento; folha.

- Foram alteradas as instruções no verso da

Depois destas modificações, o instrumento foi submetido a um estudo-piloto. Este estudo-piloto foi realizado na Unidade de Terapia Intensiva e na Unidade de Cardiologia de um Hospital Universitário Estadual no interior do Estado de São Paulo, com um total de 25 pacientes. Com os dados obtidos, foi verificada a consistência interna do instrumento pelo coeficiente Alpha de Cronbach, que apresentou um Alpha $=0,77$, valor considerado satisfatório para o ensaio. Com os dados obtidos, elaborou-se uma última modificação no item 'ambiente' em relação ao dimensionamento mínimo da área física e à conceituação de piso adequado.

Obteve-se, então, uma versão final do instrumento (Anexo). 


\section{ASPECTOS ÉTICOS DA PESQUISA}

O projeto recebeu parecer favorável do Comitê de Ética em Pesquisa da Instituição, sob o parecer $n$ 370/2000, homologado na II reunião ordinária do CEP/ FCM, em 13/02/2001.

\section{CONSIDERAÇÕES FINAIS}

Para realizar uma avaliação ergonômica em uma instituição de saúde, é importante considerar as especificidades de cada unidade e de seus clientes. A aplicação prática do instrumento desenvolvido nesta pesquisa oferecerá subsídios para o trabalhador da área de saúde, na realização de um planejamento de assistência de acordo com a dependência e as necessidades de cada cliente e do ambiente. O presente estudo validou e verificou a confiabilidade de um instrumento que foi desenvolvido para avaliar os riscos ergonômicos que podem estar presentes durante os procedimentos de movimentação e transporte de pacientes, possibilitando, dessa forma, fazer uma estimativa do tipo de assistência requerida por estes. Com isso, não só os enfermeiros, mas os trabalhadores da área de saúde terão condições de planejar de uma maneira sistemática a administração desse procedimento. $\mathrm{E}$ importante ressaltar que os resultados indicaram que o instrumento conseguiu alcançar seu objetivo, mostrando ser viável, sendo que sua utilização pode facilitar a classificação da dependência dos pacientes. Acredita-se que contribuirá para um melhor planejamento da assistência de enfermagem, juntamente com outras estratégias ergonômicas de prevenção.

$\mathrm{O}$ instrumento deve ainda, auxiliar o trabalhador na realização desse planejamento de forma individual, e o acompanhamento da evolução de cada cliente, quanto a sua dependência. A partir desse planejamento, o trabalhador da área de saúde terá condições de organizar suas tarefas e definir o melhor método de transferência e movimentação, como também escolher os equipamentos que serão utilizados na realização desses procedimentos, melhorando assim sua qualidade de vida dentro de seu ambiente de trabalho.

A avaliação das qualidades psicométricas do instrumento foi realizada através da validade do constructo e da confiabilidade (teste-reteste e interobservadores) e deverá ser publicado em seguida. Porém, neste momento fica a sugestão de que este instrumento poderá ser também usado em pesquisas relacionadas com o tema, sugerindo que outros profissionais devam utilizar o mesmo, tanto pela praticidade de preenchimento, quanto pela sua contribuição no processo de prevenção de problemas no sistema osteomuscular.

\section{REFERÊNCIAS BIBLIOGRÁFICAS}

(1) Marras WS. Occupational low back disorder causation and control. Ergonomics 2000; 43:880-902.

(2) Jensen RC. Disabling back injuries among nursing personnel: reasearch needs and justification. Res Nurs Health 1987; 10:29-38.

(3) Fuortes LJ, Shi Y, Zhang M, Zwerling C, Schootman M. Epidemiology of back injury in University Hospital Nurses from review of workers' compensation recordes and case control survey. J Occup Med 1994; 36:1022.6.

(4) Leigthon DJ, Reilly T. Epidemiological aspects of back pain: the incidence and prevalence of back pain in nurses compared to the general population. Occup Med 1995; 45:263-7.

(5) French P, Flora LF, Ping LS, Bo LK, Rita WH. The prevalence and cause of occupational back pain in Hong Kong registered nurses. J Adv Nurs 1997; 26:380-8.

(6) Smedley J, Egger P, Cooper C, Coggon D. Prospective cohort study predictors of incident low back pain in nurses. BMJ 1997; 314: 1225-8.

(7) Ando S, Ono Y, Shimaoka M, Hiruta S, Hattori Y, Hori F, Takeuchi Y. Associations of self estimated workloads with musculoskeletal symptoms among hospital nurses. Occup Environ Med 2000; 57:211-6.

(8) Niedhmmer I, Lert F, Marne MJ. Back pain and associated factors in French nurses. Int Arch Occup Environ Health 1994; 66:349-57.

(9) Conrad KM, Lavender SA, Reichelt PA, Meyer FT. Initiating an ergonomic analysis: a process for jobs with highly variable tasks. AAOHN J 2000; 48:423-9:

(10) Waters J. Hidden hazards associated with moving and handling. Community Nurse 1998; 4:21-2.

(11) Zhuang Z, Stobbe TJ, Hsiao H, Collins JW, Hobbs GR. Biomechanical evalution of assistive devices for transferring residents. Appl Ergon 1999; 30:285-94.

(12) Alexandre NMC. Contribuição ao estudo das cervicodorsolombalgias em Profissionais de enfermagem. [tese] Ribeirão Preto (SP): Escola de Enfermagem da USP; 1993.

(13) Zanon E, Marziale MHP. Avaliação da postura corporal dos trabalhadores de enfermagem na movimentação de pacientes acamados. Rev Esc Enferm USP 2000; 34:26-36.

(14) Mcabee RR. Nurses and back injuries. AAOHN J 1988; 36:200-9.

(15) Larese F, Fiorito A. Musculoskeletal disorders in hospital nurses: a comparison between two hospitals. Ergonomics 1994; 37:1205-11.

(16) Lee Y, Chiou W. Risk factors for low back pain, and patienthandling capacity of nursing personnel. J Safety Research $19941 ; 25: 135-45$ 
(17) Estryn-Behar M. Ergonomia y salud en el trabajo (I). Rev Enferm Rol 1996; 215-216:25-30.

(18) Feldstein A, Vollmer W, Valanis B. Evaluating the patientehandling tasks of nurses. J Occup Med 1990; 32:1009-13.

(19) Hignett S. Work-related back pain in nurses. J Adv Nurs 1996; 23:1238-46.

(20) Engkvist I. et al. Back injuries among nursing personnel identification of work conditions with cluster analyis. Safety Science 2001; 37:1-18.

(21) Billin SL. Moving and handling pratice in neuro-disability nursing. Br J Nurs 1998; 7:574-9.

(22) Kjellberg K, Johnsson C, Proper K, Olsson E, Hagberg M. An observation instrument for assessment of work tecnique in patient transfer tasks. Appl Ergon 2000; 31:13950.

(23) Sell I. Contribuição da ergonomia na segurança do trabalho. Rev Bras de Saúde Ocup 1990; 18:44-9.

(24) Dehlin O, Jaderberg E. Perceived exertion during patiente lifts. Scand J Rehabil Méd 1982; 14: 11-20.

(25) Bevilacqua F, Bensoussan E, Silva JMJ. Manual do exame clínico. Rio de Janeiro: Cultura Médica; 1991.

(26) Imai MFP. Avaliação neurológica do paciente inconsciente em unidade de terapia intensiva. In: Cintra EA, Nishide VM, Nunes WA. Assistência de enfermagem ao paciente crítico. São Paulo: Atheneu, 2000. p. 377-89.

(27) Dalgalarrondo P. Psicopatologia e semiologia dos transtornos mentais. Porto Alegre: Artes Médicas; 2000.

(28) Gama DDS, Sacramento MTP, Sampaio VRC. Moderna assistência de enfermagem. São Paulo: Everest, 1998.

(29) Mahoney FI, Barthel DW. Functional evalution: The Barthel Index. Md State Med J 1965; 14:61-5.

(30) Mcdowel I, Newell C. Measuring health: a guide to rating scales and questionnaires. Oxford: Oxford University Press, 1996. Physical disability and handicap. p.47-121.

(31) Mcatamney L, Corlett, EN. Ergonomic workplace assessment in a health care context. Ergonomics 1992; 35:965-78

(32) Alexandre NMC, Angerami ELS. Avaliação de determinados aspectos ergonômicos no transporte de pacientes. Rev Bras Saúde Ocup 1993; 21:81-90.

(33) Bell F. Ergonomic aspects of equipament. Int J Nurs Stud 1987; 24:331-7.

(34) Mcatamney L, Hignett SA. Space to move in. Nurs Times 1993; 89:44-6.

(35) Alexandre NMC. Aspectos ergonômicos relacionados com o ambiente e equipamentos hospitalares. Rev Lat Am Enferm 1998, 6:65-72.

(36)
Alexandre NMC. Ergonomia e as atividades ocupacionais da enfermagem. Rev Esc Enferm USP 1998, 32:84-90.

(37) Alexandre NMC, Silva FB, Rogante MM. Aparatos utilizados em la movilización de pacientes: um enfoque ergonômico. TEA 2001, 9:19-23.

(38) Ministério da Saúde. Normas para projetos físicos. Brasília; 1995.

(39) Ministério da Saúde. Portaria n. 3432/GM de 12 de agosto de 1998. Estabelece critérios de classificações para as Unidades de Tratamento Intensivo - UTI. Brasília; 1998.

(40) Polit DF, Hungler BP. Fundamentos de pesquisa em enfermagem. Porto Alegre: Artes Médicas; 1995.

(41) Lobiondo-Wood G, Haber J. Nursing research: methods, critical appraisal, and utilization, St. Louis: Moby; 1998. Reliability and validity; p. 327-50.

(42) Contandriopoulos A. Saber preparar uma pesquisa. 3. ed. São Paulo - Rio de Janeiro: Hucitec/Abrasco; 1999. Planificação operacional da pesquisa; p. 57-119.

\section{Artigo recebido em 12/01/02}

Artigo aprovado em 23/10/02 


\section{ANEXO}

\section{ESCALA DE AVALIAÇÃO DO RISCO NA MOVIMENTAÇÃO E TRANSFERÊNCIA}

Nome:

Unidade:

Idade:

Data de internação:

Leito:

Diagnóstico

Enumere um valor de 1 a 3 de acordo com a avaliação para cada item, e verifique no verso da folha as definições para cada item citado.

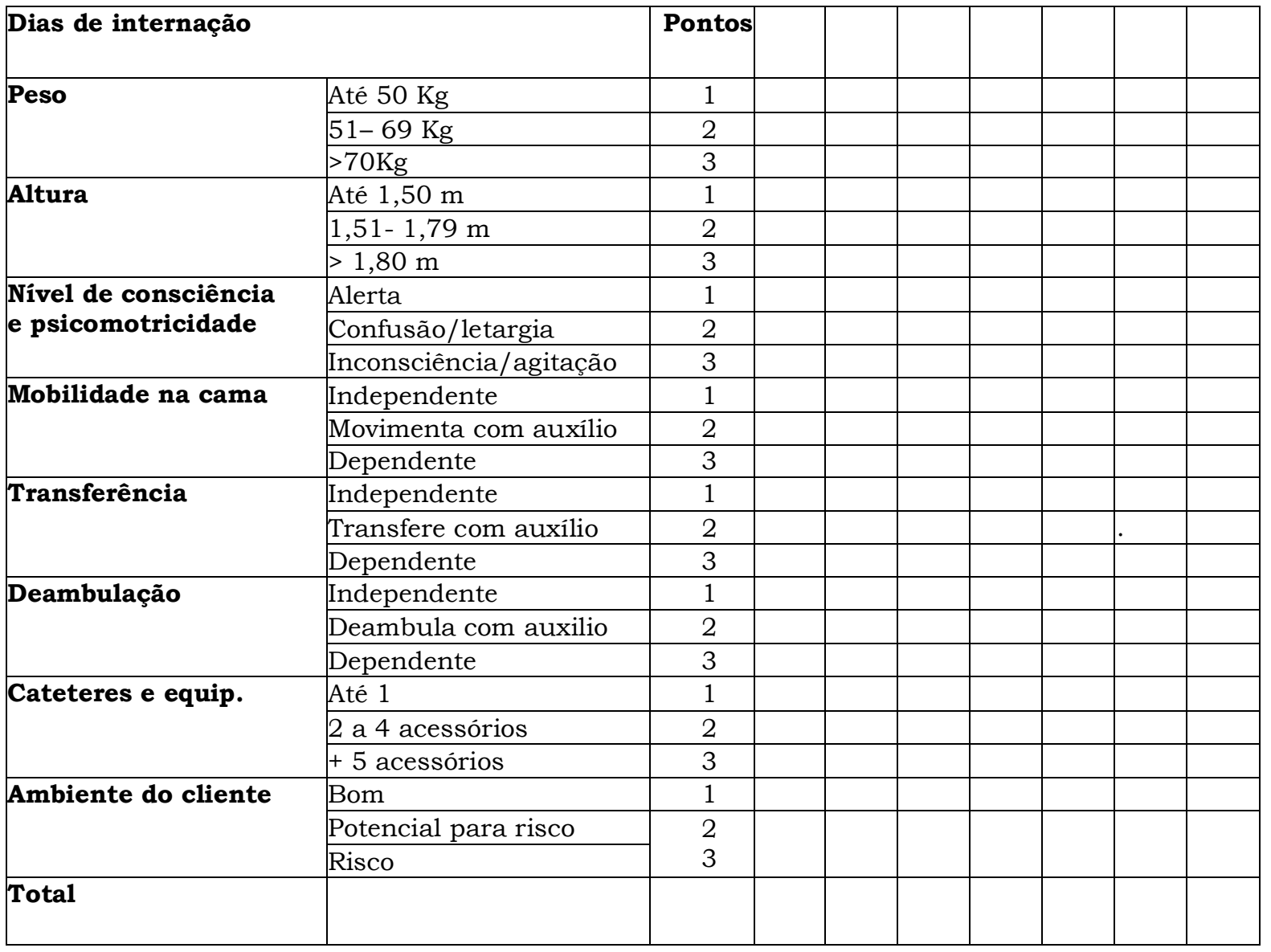

Pontuação e método de movimentação e transferência do cliente:

08-12= Pouco risco durante a movimentação e transferência do cliente;

Não necessita de auxílio, requer supervisão da equipe de enfermagem.

13-18= Médio risco durante a movimentação e transferência do cliente;

Necessita de planejamento, auxílio da equipe de enfermagem e de pequenos equipamentos (plásticos deslizantes, pranchas, cintos, barra tipo trapézio no leito, escada de cordas, discos giratórios, tábua de transferência, blocos de mão antiderrapantes).

19-24= Muito risco durante a movimentação e transferência do cliente;

Necessita de um rigoroso planejamento, auxílio da equipe de enfermagem e de equipamentos mecânicos (elevadores mecânicos). 


\section{Definições}

1- Peso

$1=$ equivale ao peso até $50 \mathrm{~kg}$;

$2=$ indica um peso de $51 \mathrm{~kg}$ a $69 \mathrm{~kg}$;

$3=$ o cliente deverá pesar igual ou superior a $70 \mathrm{~kg}$.

2-Altura

$1=$ equivale a uma altura até $1,50 \mathrm{~m}$;

$2=$ equivale a estatura entre $1,51 \mathrm{~m}$ e $1,79 \mathrm{~m}$;

$3=$ indica que o cliente possui estatura igual ou superior. a $1,80 \mathrm{~m}$.

3- Nivel de consciência e psicomotricidade

1 = alerta: o cliente responde apropriadamente aos mínimos estímulos, e na ausência deles está desperto e parece perceber o meio; $2=$ confusão! letargia

- confusão: o cliente tem alteração ainda que transitória do nível de consciência, alteração da orientação e atenção, possivel (mas não é obrigatória) distúrbios da senso-percepção (ilusões, alucinações) e do julgamento (idéias delirantes). Pode apresentar alguma inquietação motora;

- letargia: o cliente pode parecer lento ou hesitante ao falar, aos estímulos tátil e verbal ele responde apropriadamente e torna-se mais alerta, pode manifestar confusão diante de problemas complexo;

$3=$ inconsciência/agitação psicomotora:

- inconsciência: o cliente não percebe impressões sensoriais devido às alterações estruturais/funcionais ou por indução de drogas;

- agitação psicomotora: é a aceleração e exaltação de toda atividade motora do indivíduo, geralmente secundária a um taquipsiquismo acentuado. Comumente associa-se á hostilidade e à heteroagressividade.

\section{4- Mobilidade na cama}

1= independente: o cliente realiza todos os movimentos, mexe os membros inferiores e superiores, vira o corpo para os fados, senta-se na cama, sem necessitar de auxílio;

$2=$ movimenta-se com auxílio: o cliente mexe os membros inferiores e superiores, consegue virar parcialmente, o corpo para os lados e só se senta na cama com auxílio;

$3=$ dependente: o cliente não consegue mexer os membros inferiores e superiores, depende totalmente da equipe de enfermagem.

5- Transferência da cama/maca para cama/cadeira e vice-versa

$1=$ independente: o cliente consegue sentar-se na cama ou virar o corpo e transferir-se sem ajuda, e fazer o processo de retorno para cama,

$2=$ transfere-se com auxílio: o cliente consegue mexer os membros superiores e inferiores, vira o corpo parcialmente e para transferir-se necessita da supervisão e auxílio da equipe de enfermagem, como também para fazer o processo de retorno para a mesma; $3=$ dependente: o cliente não realiza nenhum movimento citado acima, depende totalmente da equipe de enfermagem.

6- Deambulação

1 = independente: o cliente deambula sem necessitar de auxílio da enfermagem/órteses e próteses;

2= deambula com auxilio: o cliente necessita de auxilio e supervisão da equipe de enfermagem;

3 = dependente: 0 cliente não deambula.

\section{7- Cateteres e equipamentos utilizados pelo cliente}

1= Até um: o cliente não possui nenhum ou possui até um acessório ou equipamento conectado;

2 = Dois a quatro acessórios: o cliente possui de dois a quatro acessórios ou equipamentos conectado;

3= Mais de cinco acessórios: o cliente possui cinco ou mais acessórios ou equipamentos conectados.

Considera-se acessórios e cateteres como: sonda vesical, nasogástrica/enteral, drenos, soros, cateteres periféricos e centrais, bolsas de colostomia.

Em relação aos equipamentos: monitores, respiradores, bomba de infusão, oxímetros, máquina de hemodiálise, balão intra-aórtico, gerador de marcapasso, colchão hipo/hipertérmico, tração transesquelética e cutânea.

\section{8- Ambiente do cliente}

1= bom: quando o ambiente não proporciona risco, durante o processo de movimentação e transferência do cliente. Possui espaço físico e piso adequado*, camas com altura ajustável, maca/cama e cadeira com travas nas rodas.

$2=$ potencial para risco: tem a presença de um dos fatores de risco como espaço físico restrito, piso irregular ou camas sem altura ajustável, maca/cama e cadeiras sem travas na rodas.

3 = risco: quando o ambiente apresenta dois ou mais dos fatores de risco como piso irregular, espaço físico restrito ou camas sem altura ajustável, maca/cama e cadeiras sem travas na rodas.

* Dimensionamento área física/leito

- Internação geral: distância entre leitos paralelos: $1 \mathrm{~m}$, distância entre leito e paredes (lateral): 0,5m

- UाI9m2

Piso adequado: fácil limpeza e resistente, não deverá ter frestas, saliências, área molhada deverá ser revestido com material antiderrapante. 